\title{
Advantages and Countermeasures of the Development of China's Food Tourism Industry
}

\author{
Xiangyun Li \\ Sichuan Tourism University, Chengdu Sichuan, 610017, China
}

Key words: Food, Industry, Tourism, Integration development.

\begin{abstract}
At present, China's tourism activities in the form of colorful, not only includes the traditional shopping tourism, sightseeing, but also developed a knowledge, full of good fortune and other effects of leisure travel. In the current tourism market, the characteristics of food can make visitors have a strong favor, in order to make the tourist destination to attract more tourists, should use a deep heritage of the food culture carrier development of food tourism industry, to meet the tourists on unknown things, foreign cultural phenomenon of curiosity Psychological, knowledge and psychological psychology. This paper analyzes the advantages and countermeasures of the development of China's food tourism industry, and aims to ensure that the tourism industry can fully grasp the development opportunity.
\end{abstract}

\section{Introduction}

Leisure tourism is the development trend of modern tourism industry, to meet the individual needs of tourists and special hobbies, the attractiveness of tourists is much greater than sightseeing. Food tourism is an important part of leisure tourism industry, belonging to cultural tourism, special fun tourism, people's food and beverage behavior and tourism activities can be integrated as a whole, the use of food to establish a good tourist image, so that visitors experience the unique food culture, Food resources and food custom, taste the local specialties, so as to relax and enjoy life [1]. In the context of modern people's pace of life, cooking time, less and less energy, dining tends to be simple and rapid socio-economic background, China's food tourism industry is in the ascendant, the integration of development advantages, the proportion of consumption increased year by year, the market development potential , Should be based on the characteristics of the application of effective integration of development strategies.

\section{Advantages}

\section{Rich in tourism resources, many types of consumer groups}

In the environment, humanities, ethnicity, history, life habits and other factors under the influence of the formation of a wide range of food and beverage, different regions, different regions, different regions of the food produced by different methods of cooking, Diet varieties, diet and eating habits, which for the tourism industry has provided a wealth of food resources, food culture. For example, there are many local dishes in China, including Anhui cuisine, Hunan cuisine, Fujian cuisine, Zhejiang cuisine, Shandong cuisine, Cantonese cuisine and Sichuan cuisine. The local cuisine has a deep connotation of dishes, stunning culinary stunt, such as tofu shredded Such as the use of food resources in the tourism industry to develop culinary arts performing arts tourism, food health tourism, food beauty and diet tourism and other types of tourism activities, thus speeding up the development of tourism industry [2]. On the other hand, among the six constituent elements of tourism activities, "food" is the first place, the basis of tourism activities, the proportion of tourism expenditure can 
reach about 35\%, different nationalities, different sex and different ages of tourists Are eating nature, hoping to enjoy food in the food. Therefore, food tourism has a variety of types of consumer groups. For example, the purpose of leisure travel to the Expo food, taste food and other popular consumer groups, tourism purposes to business negotiations, cooking research, food research and food review mainly in the end, high-end consumer groups. Many types of consumer groups can also bring a broad space for the development of tourism and huge development potential, so that the food tourism industry has more advantages of integration development.

\section{Long travel periods long and less capital investment}

Tourism products are usually season, off-season points, and food travel is more special, natural conditions, places, seasons and time will not have a significant impact on food tourism activities can be perennial food tourism, so generally no season or off-season, this Can extend the tourist's stay in the tourist destination and increase the economic income of the tourist destination. Guilin, China's famous scenic tourist area, for example, the number of tourists each year to reach more than 10 million, but the local real tourism revenue and tourists should bring the theoretical income there is a big gap, which is limited to natural tourism products, The impact of the natural environment, the lack of innovation and national characteristics, slow update and image of a single factor. Under the influence of these factors, the average time for tourists to stay in the tourist area is shorter, and in the case of shorter travel time, the level of tourism consumption will be pulled low. In this regard, the development of food in Guilin tourism products, so that visitors enjoy the beautiful scenery in the process of taste the characteristics of food, can increase the breadth and depth of tourism, to extend the tourist travel time, increase the local tourism consumption. In addition, the integration of food and tourism industry development also has less capital investment, low cost of tourism products operating advantage. Food tourism is characterized by cultural, regional, experiential, aesthetic and other personality characteristics, in the development of tourism resources only need to properly process food products, and food products, cultural connotation of the depth of mining, you can package into a strong appeal Food tourism projects, such as tasting food products, listen to the origin of food, show food cooking and participation in customs activities, without the need for high pre-construction costs and post-maintenance costs, can effectively reduce the tourism project capital investment, but also increase tourism The economic return of the industry [3-4].

\section{Countermeasures}

\section{Integrate ecological ideas to develop green tourism food}

Pure green food is the pursuit of modern life for the material life, the integration of ecological ideas to develop green tourism food can not only effectively control the quality of food production, reduce food safety issues, to avoid the tourism market into a chaotic state, help to expand the scale of tourism industry, also Can create a suitable for tourists leisure travel consumption of food products. The development of green tourism in the process of food should be fully dependent on the local green ingredients, reflecting the ecological connotation, the use of green food to enhance the beauty of the tourist destination and word of mouth effect [5]. First of all, the choice of food cooking raw materials should be green, the principle of localization, the use of tourist sites to grow or produce cooking materials, and try to use the authority of the department identified and recognized raw materials, reduce cooking materials in the field to ensure that visitors can taste the original Authentic green tourist food. For example, the longevity tourism town of Guangxi Bama developed wild vegetables, green vegetables, tea oil, mineral water, hemp and pig and other green tourism food, green food are derived from the local planting base or production base, attracting a large number of tourists Go to tasting and purchase. Second, in the processing of green food should pay attention to simple and simple degree, the thickness of the combination, to avoid the development of tourism industry positioning. Processing green food should pay attention to retain the natural qualities, and into the appropriate artificial carving, so that food icing on the cake. For example, for the farm chicken, you 
can use fried, explosive, stew, burning and other cooking methods to highlight the main flavor of the main ingredient, try to avoid velvet and the production of chicken and other exquisite dishes to preserve the green ecological "rural flavor." In addition, the development of green food in the process should also highlight the health of quality, to retain the delicious flavor of food, so that green food nutrition balanced, distributed fresh natural atmosphere, so that visitors have a stronger attraction.

\section{Integration of the characteristics of culture to create food tourism brand}

Culture is the soul of food tourism, the characteristics of culture to enhance the scenic spots, the vitality of the attractions, so that the tourist destination by tourists of all ages, can be combined with the characteristics of culture to create food tourism brand, so that visitors can enjoy authentic and authentic food in addition to deep experience the characteristics of food culture, including listening to food legend allusions, to participate in food production. But also the national style and food culture integration, or the use of celebrity praise, like to eat a series of food series celebrity food culture, so that visitors can travel in the food to understand the history and culture, cultural style. In shaping the characteristics of food tourism brand, can be based on the characteristics of food culture to develop a variety of tourism projects, such as diet health culture tourism, religious food culture tourism, fishing and music and farm music tourism. Most tourists want to live in the tourism fitness, and can enjoy the medicated food, in order to achieve health care, so you can dietary culture in the integration of Chinese medicine health care knowledge, traditional Chinese medicine and culinary art of organic combination for the tourists to cook with Health effects of delicious food [6-7]. In addition, you can also integrate fishery and farm music culture development of food tourism. For example, the Poyang Lake tourist area to fishing family music as the theme of food tourism, fishermen for the visitors to perform fishing techniques, so that visitors live cooking fish or shrimp to take home, in the taste of fresh fish at the same time, Tourists prepared tents camping, bonfire party and fishing singing and other cultural activities.

\section{Integration of the development of multi - level food tourism system}

Integration of the development level of diversified food tourism system can make tourism products together to jointly accelerate the development of tourism industry. In the development of multi-level food tourism system should grasp the following key points. First of all, in the country to build regional food capital, the food capital is built into a tourist high ground. In the construction of the domestic food capital, should give priority to the famous dishes of the birthplace of the central city, foreign ports, tourist cities, such as Guangzhou, Yangzhou, Shanghai, Chengdu, Xi'an, Tianjin and Beijing. Second, through the construction of Food Street, food city for tourists show local food. In the tourist city, tourist county, food and other places to build food street, food city, the appropriate concentration of chefs, famous shops, old and famous, and focus on display dishes, snacks and other brand catering, to allow visitors in a limited time and space Taste more food [8]. For example, Guangdong Shantou use Chaozhou to create a series of food street, and in the combination of food street on the basis of the construction of leisure resort food city. In the creation of food city, the Shantou government played a leading role, fully activated the social resources, and according to the public tourists, high-end tourists and other food tourism market segmentation, the construction of a large number of food tourism theme blocks, such as Chaoshan snack food street, Fish pills Street, beef balls Street, etc., Shantou tourist area also uses the sea landscape to create a food boat, porridge with music, poetry and painting, visitors can enjoy Chaozhou music, poetry and painting in the process of cooking from cooking, taste snacks and Boutique Chao Cai, tourist landscape is very unique.

\section{Integration of a variety of marketing programs}

Marketing is the basis for the development of food tourism industry, in order to do marketing work, you can use the following strategy. First of all, should develop a clear food tourism activities, tourism products, investment and investment mechanism and the use of network, television, print ads, hotels and travel agencies and other promotional media to carry out marketing work. At the same time 
improve the tourism service system, provide a detailed food route map, the construction of tourism information service website, bus stations or bus stations opened tourist routes, rational distribution of scenic areas within the leisure facilities, public toilets, etc., if necessary, , The tourist service station is located near the scenic area. Second, for the tourist area of the hotel, shops and catering enterprises, should be unified food quality control standards, and planning food festival and trade fairs. In the food festival and fairs for visitors to explain the nutritional value of food, taste, origin, raw materials, production methods, etc., sales of native products, delicious snacks, so that visitors understand the characteristics of food, rich food experience, thus strengthening the marketing effect [9]. In addition, it can encourage and attract businessmen to develop easy storage, taste authentic, easy to carry and can represent the local food culture and folk customs of food products to meet the shopping needs of travel, or the characteristics of food printed on the fine card and hanging Decorated in the market to introduce food books or CDs, etc., to improve the marketing effect and increase the income of the tourism industry. For example, Hainan Sanya in the deep processing of food raw materials on the basis of the production of a variety of easy to carry instant food products, such as coconut cake, coconut rice, etc., while the development of fruit juice, vegetable juice and other gifts to facilitate others gifts, visitors back to the gift And the delivery of gifts, to enhance the reputation of tourism and visibility.

\section{Conclusions}

To sum up, China has a long history of food culture, a wide variety of food, with historical and cultural characteristics, national characteristics and geographical characteristics, should be in the tourism activities to ensure that food culture, food culture, food social values and economic values are the ultimate play, Tourists food tourism motives, the development of a broader food tourism market, so that visitors experience the process of food linger in order to promote the integration of food tourism industry development. In the development of food tourism industry, the need for cultural elements as the planning of tourism products and tourism activities at the core, pay attention to the depth of digging food resources, according to the needs of the development of tourism market tourism products, tourist destination cultural heritage, customs and local cuisine And promote and create a fresh, contemporary sense of food tourism brand. In addition, the development of food tourism industry should be inclusive, to tourists interested, agree with the modern aesthetic concept of continuous innovation and improved food varieties.

\section{Acknowledgement}

This article is a key Humanities and Social Sciences project of Sichuan Provincial Department of Education. Project number: 13SA0131.

\section{References}

[1] Zhou Wen-zhe.Study on the Impact of Tourism Development on Regional Diet Culture , Chinese Journal of Business, 2015 (14): 123-125.

[2] Luo Qiuyu, Xu Lei, On the Formation Mechanism and Main Characteristics of Diet Culture in the Three Gorges Area, Journal of Chongqing University of Arts and Science (Social Science Edition),2016,35(1):87-90.

[3] Lin Yongkun. A Preliminary Study on the Experiential Business of Hakka Architectural Culture and Traditional Style - A Case Study of Hakka Food Culture City in Haixi (Ninghua), Fujian Architecture,2015(2):28-31. 
[4] Zhang Ting, Zhang Yafei. Exploration on the Connotation of Diet Culture in Guanzhong Area of Shaanxi Province from the Perspective of Silk Road, New West (theoretical condition),2016(8):53.

[5] Ma Xiaoling. A Study on the Application of Local Culture in the Tourist Industry of Tourist Resorts - Taking Wuyi Mountain as an Example, Journal of Anhui Agricultural University (Social Science Edition),2015,24(2):130-134.

[6] Mei Junxiang, Zheng Wenjun, Liu Hui, . Discussion on Greenland Landscape Construction of Small Towns Based on Fiber Green Space - A Case Study of Guilin Tanxia International Cuisine Theme Town, Green technology, 2016(5):123-125.

[7] Yang Xiaochuan, Xue Bin, Zhang Qunying. A Study on the Innovative Marketing Model of Small Catering Enterprises Based on "Non-left" Culture - Taking Leshan "Zhoucun Ancient Eater" as an Example, Journal of CPC Leshan Municipal Party College,2014,16(2):43-45.

[8] Cai Yi, Yang Yang, Yin Hongmei. Research on Audience Perception of Guiyang City Tourism Brand Based on ROST Text Mining Software, Journal of Chongqing Normal University (Natural Science Edition),2015,32(1):126-133.

[9] Liu Jiaxue. A Study on Tourist Satisfaction of Local Gourmet Landscape - A Case Study of Nanjing Salt Water Duck, Journal of Nanjing Xiaozhuang University,2016(4):116-121. 